Probable cases of $P$ foenisecii intoxication have been described in children. Holden reported that a small boy became ill with tachycardia and mydriasis after eating $P$ foenisecii, ${ }^{3}$ but he was too young to describe adequately his subjective experience. Southcott describes a 2-year-old girl with pica who probably ate the $P$ foenisecii that grew on her parents' lawn in Adelaide. She suffered from periodic attacks of hysterical behaviour with visual and tactile hallucinations her symptoms were finally, fairly confidently, attributed to consumption of $P$ foenisecii. ${ }^{4}$

Other species of Panaeolus have been recorded as being used for ritual purposes and causing accidental poisonings. In adults distortions of perception and laughing are prominent effects, but children may react more severely with convulsions. ${ }^{2}$ Acute delirious and psychotic states and more prolonged "schizophrenia-like" conditions have been described after consumption of Psilocybe semilanceata. ${ }^{1}$

Publications exist in the United Kingdom and North America that give detailed descriptions of hallucinogenic mushrooms including $P$ foenisecii. This is a common mushroom whose use for hallucinogenic and euphoric effects seems to be increasing. Furthermore, it has been suggested that this mushroom may often be collected and eaten in error for the more widely known $P$ semilanceata (G Hadley, unpublished observations). It may produce acute perceptual distortions and have similar ill effects to LSD. There is also a risk of mistaking more-toxic fungi for these "magic mushrooms" and of young children eating adult doses.

I am grateful for the advice and assistance of Professor A S Douglas, professor of medicine, Aberdeen Royal Infirmary; Dr G Hadley, department of botany, Aberdeen University; and Dr R Watling, Royal Botanic Gardens, Edinburgh.

${ }^{1}$ Hyde C, Glancy G, Omerod P, Hall D, Taylor GS. Abuse of indigenous Psilocybin mushrooms: a new fashion and some psychiatric complications. Brit 7 Psychiat 1978;132:602-4.

2 Pollock J. Psilocybian mycetismus with special reference to Panaeolus. f Psychedel Drugs 1976;8:43-7.

${ }^{3}$ Holden M. A possible case of poisoning by Panaeolina foenisecii. Bull Brit Mycol Soc 1965;25:9-10.

4 Southcott RV. Notes on some poisoning and other clinical effects following ingestion of Australian Fungi. S Austr Clin 1975;6:441-78.

\section{Does increased movement protect smokers from postoperative deep vein thrombosis?}

Clayton et al have shown that cigarette smoking is associated with a decreased incidence of postoperative deep venous thrombosis. ${ }^{1}$ Pollock and Evans ${ }^{2}$ have reported that among surgical patients cigarette smokers are younger and thinner than non-smokers and therefore less likely to suffer from postoperative deep venous thrombosis, but they concluded that this is certainly not the whole explanation. Coagulation studies have shown no difference between the blood of the smoker and the non-smoker. ${ }^{3}$ We postulated that patients who are smokers may be protected postoperatively against deep venous thrombosis because they move more-possibly for a surreptitious cigarette in the bathroom.

\section{Patients, methods, and results}

We tested this theory in 40 patients undergoing inguinal herniorrhaphy. We recorded their movement with a sensitive pedometer worn in their pyjamacoat pocket. All patients undergoing the operation wore the pedometer for 24 hours preoperatively and until the fourth day after operation. The patients were divided into smokers and non-smokers and their ages recorded. The median age of the non-smokers was 54.5 years (range 48-65), whereas that of the smokers was 47 years (range 33.5-53.5). This difference was significant $(p<0.025)$. Smokers smoked an average of 22 cigarettes a day.
For the 24 hours before operation the median distance moved by the smokers was $2.01 \mathrm{~km}$ (range $1.77-2.25$ ) and by the non-smokers $1.93 \mathrm{~km}$ (range 1.28-2.9). This difference was not significant $(\mathrm{p}=0.52)$. On the fourth postoperative day the smokers had walked $3.06 \mathrm{~km}$ (range $2 \cdot 09-4.51$ ) since the operation and the non-smokers $2 \cdot 41 \mathrm{~km}$ (range 1.61-4.42). Again this difference was not significant $(\mathrm{p}=0 \cdot 68)$.

\section{Comment}

We conclude that there is no difference between the movements of smokers and non-smokers after operation and therefore that smokers are not protected from deep venous thrombosis by increased movement. The reason for the decreased incidence of thrombosis in smokers remains a mystery.

1 Clayton JK, Anderson JA, McNicol GP. Effect of cigarette smoking on subsequent postoperative thromboembolic disease in gynaecological patients. Br Med f 1978;ii:402.

${ }^{2}$ Pollock AV, Evans M. Cigarette smoking and postoperative deep venous thrombosis. Br Med $\mathcal{F}$ 1978;ii:637.

3 Clayton JK, Anderson JA, McNicol GP. Preoperative prediction of postoperative deep venous thrombosis. $\operatorname{Br} \operatorname{Med} \mathcal{F} 1976$;ii:910-12.

(Accepted 29 November 1979)

Surgical Unit, Gordon Hospital, London SW1V 2RF

T E BUCKNALL, FRCS, surgical registrar

T BOWKER, MB, CHB, house surgeon

D J LEAPER, MD, FRCS, senior surgical registrar

\section{Outcome of pregnancy after spontaneous abortion}

A recent report from Liverpool $^{1}$ suggested that there may be a fourfold increase in congenital malformations in the pregnancy after a spontaneous abortion. Only a few cases were studied, and the authors called for studies from elsewhere. It has been generally accepted that a history of abortion, stillbirth, or neonatal death indicates an increased risk of subsequent obstetric problems. ${ }^{2}$ In certain patients-for example, a woman who aborted a fetus with anencephaly-one would expect an increased risk of a further neural tube defect in subsequent pregnancies. No one to our knowledge, however, has suggested a risk of malformations in general on the scale found in the Liverpool study, and we thought that this warranted further investigation in a slightly different way.

\section{Patients, methods, and results}

We studied the case notes of women who had delivered a baby at the old Bristol Maternity Hospital. The notes at the old hospital were conveniently filed according to the year of the mother's most recent delivery, and we selected a group of women whose final delivery was in either 1969 or 1970 .

We excluded as malformations the following: clicking and dislocated hips, talipes, innocent systolic murmur, and undescended testicle. We included chromosome abnormalities, sacral dimples and sinuses, and hydroceles, so that our figures could be more easily compared with those of the Liverpool group.

We examined the records of 2633 pregnancies to see whether the outcome

Outcome of index pregnancy and outcome of subsequent pregnancy in 2633 patients. Results are given as number of cases with percentages in parentheses

\begin{tabular}{lrrrrr}
\hline \multirow{2}{*}{$\begin{array}{c}\text { Outcome of } \\
\text { index } \\
\text { pregnancy }\end{array}$} & No & \multicolumn{4}{c}{ Outcome of subsequent pregnancy } \\
\cline { 3 - 7 } & & Normal & $\begin{array}{c}\text { Spontaneous } \\
\text { abortion }\end{array}$ & $\begin{array}{c}\text { Mal- } \\
\text { formation } \dagger\end{array}$ & $\begin{array}{c}\text { Anatomically } \\
\text { normal } \\
\text { stillbirths }\end{array}$ \\
\hline Normal & 2107 & $1824(86 \cdot 6)$ & $213(10 \cdot 1)$ & $51(2 \cdot 4)$ & $19(0 \cdot 9)$ \\
Spontaneous abortion & 440 & $304(69 \cdot 1)$ & $120(27 \cdot 3)$ & $10(2 \cdot 3)$ & $6(1 \cdot 4)$ \\
Stillbirth & 45 & $37(82 \cdot 2)$ & $5(11 \cdot 1)$ & $3(6 \cdot 7)$ & 0 \\
Major malformation* & 41 & $30(73 \cdot 2)$ & $9(22 \cdot 0)$ & $1(2 \cdot 4)$ & $1(2 \cdot 4)$ \\
\hline Total & 2633 & 2195 & 347 & 65 & 26
\end{tabular}

*Major malformation included cases of spina bifida, hydrocephalus, anencephalus, congenital heart disease, malformations of the gut, and cleft palate. †Live-born and stillborn babies were included in this category. 
of a preceding pregnancy had any effect on the outcome of the subsequent pregnancy. A first, second, or third pregnancy was taken as the index pregnancy and the outcome of the subsequent pregnancy examined.

The distribution of social classes in the sample was: class I, $12 \%$; class II, $16 \%$; class III, $48 \%$; class IV, $13 \%$; class V, $4 \%$; and $7 \%$ of patients were of unknown social class.

The table shows the outcome of the pregnancy after the index pregnancy. There were 51 malformations after a normal pregnancy $(2.4 \%)$ and 10 after a spontaneous abortion $(2.3 \%)$. Nine $(18 \%)$ of the malformations after a normal pregnancy were of the central nervous system (CNS), as were four $(40 \%)$ of the malformations after a spontaneous abortion.

\section{Comment}

The rate of malformations in the subsequent pregnancies was the same whether these followed a normal pregnancy or a spontaneous abortion. These findings failed to confirm the suggestion of an increased rate of malformations after a spontaneous abortion. ${ }^{1}$ The rate of malformations of the CNS, however, was higher after a spontaneous abortion, but some of these aborted fetuses probably also had defects of the CNS. The rate of spontaneous abortions after a previous abortion was increased more than twofold, and it also appeared that there might be an increased rate of abortions after a major malformation, but here the numbers were small.

We conclude that women who have had a spontaneous abortion are not at any overall increased risk of a malformation in their next pregnancy. The chances that the next pregnancy will again end in abortion are increased, and there is probably a very small increased risk (under one in 100) of the fetus having a defect of the CNS.

We thank our colleagues in Liverpool for helpful discussion and encouragement and an anonymous donor for financial support.

Full data of this survey are available from Dr T J David.

1 Gardiner A, Clarke CA, Cowen J, Finn R, McKendrick OM. Spontaneous abortion and fetal abnormality in subsequent pregnancy. $\mathrm{Br} \mathrm{Med} \mathcal{F}$ $1978 ; \mathrm{i}: 1016-8$

${ }^{2}$ Fedrick J, Adelstein P. Preceding pregnancy loss as an index of risk of stillbirth or neonatal death in the present pregnancy. Biol Neonate $1977 ; 31: 84-93$.

(Accepted 29 November 1979)

Booth Hall Children's Hospital, Blackley, Manchester M9 2AA

T J DAVID, MRCP, DCH, acting consultant paediatrician

Bristol Maternity Hospital, Bristol BS2 8EG

CAROLINE M SMITH, SRN, SRM, in-course training sister

\section{Indomethacin and perforated duodenal ulcer}

Cooke $^{1}$ found that only $5.5 \%$ of 634 patients taking indomethacin had a peptic ulcer, no greater than the general population. A six-year review of perforated duodenal ulcers in Exeter showed that out of 21 perforations in women aged over $60,8(38 \%)$ were taking indomethacin. A group matched for age and sex were studied to see whether this association was due to a high intake of indomethacin around Exeter.

\section{Patients, methods, and results}

The notes of 89 patients admitted to the Royal Devon and Exeter Hospitals between January 1970 and December 1975 with perforated duodenal ulcer were reviewed. Eleven $(12 \%)$ were taking indomethacin. Eight $(38 \%)$ of the women aged over 60 in the group were taking indomethacin (table). Nine patients were taking the indomethacin by mouth, one by suppository, and one by both methods. Three patients were also taking either prednisolone $2.5 \mathrm{mg}$ four times a day, corticotrophin $15 \mathrm{mg}$ weekly, or aspirin. Four patients were taking indomethacin for osteoarthritis, five for rheumatoid arthritis, one for gout, and one patient for arthritis of indeterminate type. In contrast to the short preoperative dyspepsia of many of these patients 10 were found at operation to have chronic ulcers. In two cases these involved the liver and surrounding structures.

The notes of 222 women over the age of 60 who were admitted to the same hospitals with gall stones between January 1971 and December 1975 were also reviewed. These patients had a similar distribution according to age as had the patients with a perforated duodenal ulcer. None were recorded as taking indomethacin (table) although 12 were recorded as having arthritis. There was no record of current medication in five patients.

\section{Comment}

Non-steroidal anti-inflammatory analgesics are often implicated in the aetiology of peptic ulceration but, apart from aspirin ${ }^{2-5}$ and phenylbutazone, ${ }^{5}$ there is little statistical evidence. ${ }^{1}$ If the association between indomethacin and perforated duodenal ulcer in Exeter simply reflected a high level of ingestion of the drug about 100 of the 222 women over the age of 60 admitted to the same hospitals with gall stones would have been expected to be taking indomethacin. In fact, none were recorded as taking it. This difference was statistically significant (table). Possibly some of the patients with gall stones were taking indomethacin and this was not recorded. This is unlikely since most of them were routine admissions for cholecystectomy and had in their notes a record of their current medication filled in by their general practitioner. Also only 12 of them were recorded as having arthritis. Even if all these and those whose current medication was not recorded had been taking indomethacin the incidence of indomethacin ingestion would still be significantly less in patients with gall stones (table). One must conclude from these

Incidence of indomethacin ingestion in women aged over 60 presenting with either perforated duodenal ulcer or gall stones

\begin{tabular}{|c|c|c|c|c|}
\hline & $\begin{array}{l}\text { Patients } \\
\text { with } \\
\text { perforated } \\
\text { duodenal } \\
\text { ulcer }\end{array}$ & $\begin{array}{l}\text { Patients } \\
\text { with gall } \\
\text { stones }\end{array}$ & Total & $\begin{array}{l}\text { Statistical } \\
\text { significance }\end{array}$ \\
\hline $\begin{array}{l}\text { Taking indomethacin } \\
\text { Not taking indomethacin }\end{array}$ & $\begin{array}{r}8 \\
13\end{array}$ & $\overline{217}$ & $\begin{array}{r}8 \\
230\end{array}$ & $\begin{array}{l}\chi^{2}=74.22 \\
\mathrm{p}<0.001\end{array}$ \\
\hline Total & 21 & 217 & 238 & \\
\hline $\begin{array}{l}\text { Taking indomethacin plus } \\
\text { drugs not recorded } \\
\text { The rest }\end{array}$ & $\begin{array}{r}8 \\
13\end{array}$ & $\begin{array}{r}5 \\
217\end{array}$ & $\begin{array}{r}13 \\
230\end{array}$ & $\begin{array}{l}\chi^{2}=41.85 \\
\mathrm{p}<0.001\end{array}$ \\
\hline Total & 21 & 222 & 243 & \\
\hline $\begin{array}{l}\text { Taking indomethacin plus } \\
\text { drugs not stated plus } \\
\text { patients with arthritis } \\
\text { The rest }\end{array}$ & $\begin{array}{r}8 \\
13\end{array}$ & $\begin{array}{r}17 \\
205\end{array}$ & $\begin{array}{r}25 \\
218\end{array}$ & $\begin{array}{l}\chi^{2}=16.10 \\
\mathrm{p}<0.001\end{array}$ \\
\hline Total & 21 & 222 & 243 & \\
\hline
\end{tabular}

figures that indomethacin is a major predisposing factor to perforation in duodenal ulcer, particularly in the elderly.

One patient in this series was also receiving prednisolone and another corticotrophin injections. Possibly in these cases corticosteroids were also predisposing factors. A striking feature of this group of perforations is the discrepancy between the chronicity of the ulcer found at operation and the preoperative symptoms. Large and penetrating ulcers gave rise to very few symptoms. Although many would advocate a conservative surgical approach in treating these patients it is notable that two of the ulcers in this series bled postoperatively, one despite vagotomy and pyloroplasty, and that all except two patients had chronic ulcers.

I thank Messrs H D Moore, M Golby, A J Knox, C Shaldon, and K D Vowles for allowing me to review their cases and Mrs A F Morris for statistical help.

${ }^{1}$ Cooke AR. Drugs and gastric damage. Drugs 1976;11:36-44.

2 Douglas RA, Johnston ED. Aspirin and chronic gastric ulcer. Med f Aust $1961 ; 2: 893-7$.

${ }^{3}$ Duggan JM, Chapman BL. The incidence of aspirin ingestion in patients with peptic ulcer. Med $\mathcal{F}$ Aust 1970;1:797-800.

4 Levy M. Aspirin use in patients with major upper gastrointestinal bleeding and peptic ulcer disease. A report from the Boston Collaborative Drug Surveillance Program, Boston University Medical Center. $N$ Engl $\mathfrak{f}$ Med $1974 ; 290: 1158-62$.

5 Glarborg Jorgenson. Drug consumption before perforation of a peptic ulcer. Br ₹ Surg 1977;64:247-9.

(Accepted 20 November 1979)

Royal Devon and Exeter Hospitals, Exeter, Devon

M R THOMPSON, MB, FRCS, senior registrar 